\title{
Adverse Childhood Experiences in Infancy: a Latent Class Approach Exploring Interrelatedness of Risks
}

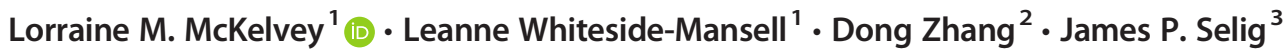 \\ Published online: 11 February 2020 \\ (C) The Author(s) 2020
}

\begin{abstract}
Researchers have documented the ways in which children's parenting and home environments impact their social, emotional, and cognitive skills. There is scientific consensus that certain adverse childhood experiences (ACEs), particularly in the absence of a nurturing caregiver, decrease the likelihood that children will develop optimally. Many ACEs co-occur, thereby increasing the number of adversities children experience. This study examined the interrelatedness of ACEs for 14-month-old children from the Early Head Start Research and Evaluation Project $(N=2361)$. Using latent class analysis, three classes were identified: ACEslow $(N=1431,60.6 \%)$, ACEs-parent maltreatment $(N=636,26.9 \%)$, and ACEs-household dysfunction $(N=294,12.5 \%)$. Class membership was significantly associated with related parenting constructs. Children in families with greater household dysfunction (ACEs-household dysfunction) had parents with the highest levels of parenting stress and the lowest levels of self-efficacy, but who were knowledgeable of infant development and were observed to be moderately supportive in play with their child. Parents at risk for child maltreatment (ACEs-parent maltreatment) had moderate levels of stress and self-efficacy, but the least knowledge of development and were observed to be the least supportiveness in play. Our study suggests that infants experience constellations of ACEs, which are differentially associated with parenting characteristics and behaviors. Results lend credibility to ACE screening in infancy and could be used to inform intervention efforts and the development of more efficient, sensitive screening methods.
\end{abstract}

Keywords Adverse childhood experiences $\cdot$ Infancy $\cdot$ Parenting $\cdot$ Latent class analysis

There is scientific consensus that certain childhood experiences decrease the likelihood that children will develop optimally (Bethell et al. 2017; Shonkoff 2010). Developmental researchers have documented the ways parenting and home environments threaten the development of social, emotional, and cognitive skills (Belsky 1984; Bradley and Corwyn 2002). A wealth of research has examined the associations between child

Lorraine M. McKelvey

mckelveylorraine@uams.edu

1 College of Medicine, Department of Family and Preventive Medicine, University of Arkansas for Medical Sciences, $4301 \mathrm{~W}$. Markham, Little Rock, AR 72205, USA

2 College of Liberal Arts and Sciences, Department of Health and Human Physiology, University of Iowa, 225 S Grand Ave, Iowa City, IA 52240, USA

3 College of Public Health, Department of Biostatistics, University of Arkansas for Medical Sciences, 4301 W. Markham, Little Rock, AR 72205, USA maltreatment and environmental risks, such as parental depression and substance use, and child development and health (Hildyard and Wolfe 2002; Springer et al. 2007). In addition, cumulative risk studies postulate that risk from a single factor is less powerful than a combination of risks and routinely find a linear relationship between the number of risks and negative developmental outcomes (Evans et al. 2013; Sandler 2001).

\section{Adverse Childhood Experiences and Cumulative Risk Indices}

Psychologists have discussed the negative impact of exposure to multiple risks in home and caregiving environments, but the link between a specific array of stressful and potentially traumatic childhood events associated with problems in health and wellbeing in adulthood has garnered much public attention. The Adverse Childhood Experiences (ACEs) study documented a set of specific events in childhood linked to chronic diseases and even early mortality in adulthood (Anda et al. 2006; Felitti 
et al. 1998). The ACEs study, like other studies of cumulative risk, found strong and linear relationships between developmental outcomes and the number of early childhood risks. As the number of risks increased, the likelihood of less optimal outcomes also increased. Anda et al. (2006) reported that individuals with the highest number of ACEs experienced nearly three times the number of comorbid outcomes compared with those with no risk exposure.

The ACE Index includes ten indicators (Kaiser-ACEs; Anda et al. 2006; CDC n.d.; Felitti 1993). Half of the indicators assess child maltreatment, including physical, sexual, and emotional abuse and physical and emotional neglect. The remaining five indicators are characteristics of the parent or home environment. These include living with a family member with a mental illness, a substance use problem, a history of incarceration, living in a home with domestic violence, or living in a home with parents who have separated or divorced. Using data from the Behavioral Risk Factor Surveillance System (BRFSS), the Centers for Disease Control reported $59 \%$ of adults in 10 US states have experienced exposure to one or more ACEs (Centers for Disease Control and Prevention 2016). National Survey of Children's Health data suggests $33.3 \%$ of children aged birth to 17 in the USA have experienced at least one family adversity (Health Resources and Services Administration 2019).

While the findings for cumulative risk indices and the ACE Index are robust, there are potential weaknesses in their design. One concern is that each of the risks examined in a cumulative study is weighted equally. This has given rise for concern in the study of outcomes, particularly as risks do not often assume equal prevalence for predicting difficulties in development. For example, ACEs include sexual abuse and parental divorce/separation. Both are associated with less optimal outcomes, but the extant literature suggests that sexual abuse is a more robust predictor of developmental outcomes.

Further, theoretical models of parenting and empirical studies suggest that these childhood adversities are likely to co-occur (Dong et al. 2004; Green et al. 2010; McLaughlin et al. 2012). Researchers have examined childhood maltreatment as a multidimensional construct, in part, to model the substantial cooccurrence of childhood maltreatment experiences (Armour et al. 2014; Berzenski and Yates 2011; Rivera et al. 2018; Schilling et al. 2015). In retrospective studies of adults, there is a relatively high co-occurrence of adverse experiences in childhood (Dong et al. 2003, 2004; Edwards et al. 2003; Ford et al. 2014). Indeed, studies report that experiencing one childhood ACE increases the odds that the individual will also report other adversities (Dong et al. 2004).

\section{Studies of Interrelated Risks in Adult Samples}

Researchers have employed different analytic strategies for understanding the interrelatedness of ACEs. In adult populations, there have been multiple studies of ACEs using variable-centered analyses, such as factor analytic techniques. These studies have been conducted primarily using the Behavioral Risk Factor Surveillance System (BRFSS). It is important to note, when comparing findings across studies, that the BRFSS ACEs module excludes the measurement physical and emotional neglect, ultimately assessing eight of the 10 Kaiser-ACEs (Centers for Disease Control and Prevention 2016). Two separate studies identified three factors: household dysfunction, emotional/physical abuse, and sexual abuse (Brown et al. 2013; Ford et al. 2014). Focusing solely on low-income women, other researchers found two overall factors: household dysfunction and abuse/ neglect (Mersky et al. 2017). Household dysfunction and abuse/neglect factors have also been found using data from the National Comorbidity Survey Replication (NSCR); however, an additional factor of interpersonal loss (e.g., parental death or separation) was also identified (Green et al. 2010).

There is a new, but growing literature that examines the interrelatedness of adult-reported ACEs using personcentered methods. In a study of college students who reported on BRFSS-ACEs, latent class analysis (LCA) identified four classes of individuals: low-risk, household dysfunction, emotional/physical abuse, and a class with high levels of all ACEs (Merians et al. 2019). The largest study using BRFSSACEs data $(N=117,555)$ reported more combinations of exposures including (1) low-risk; (2) sexual abuse; (3) emotional abuse and household alcoholism; (4) emotional abuse, household alcoholism, and domestic violence; and (5) high levels of all ACEs (Barboza 2018). Two studies have also explored ACEs and additional indicators or community/environmental violence. Both identified a low- and a high-risk ACEs class. One of these studies identified two additional classes of household dysfunction/community violence and emotional ACEs (Shin et al. 2018), while the other identified community indicators as a separate class (Rebbe et al. 2017).

Two studies have used data from the National Epidemiologic Survey on Alcohol and Related Conditions (NESARC) to examine the interrelatedness of ACEs. NESARC-ACEs are similar to BRFSS-ACEs with the inclusion of physical neglect and exclusion of parental divorce/ separation. A study of 34,653 adults resulted in classes characterized by (1) low-risk, (2) caregiver substance use and neglect, (3) emotional/physical abuse, (4) caregiver maladjustment, and (5) severe cross-subtype maltreatment and caregiver substance use (Roos et al. 2016). Findings from a large sample of veterans $(n=36,309)$ identified similar groups of low risk and maltreatment with household substance use, but also identified severe maltreatment with moderate household dysfunction and a class with high levels of all ACE indicators (Ross et al. 2018). 


\section{Studies of Interrelated Risks in Pediatric Studies}

In pediatric samples, examinations of the interrelatedness of ACEs are limited. One study examined parent-reported Kaiser-ACEs for youth under the age of 17 years (median age 7) and, using exploratory factor analysis, reported three factors: abuse, household dysfunction, and a mixed factor (Scott et al. 2013). The majority of studies examining ACEs in children have used person-centered analytic techniques. A study of 92,017 adolescents in the Florida juvenile justice system reported five clusters: (1) low-risk; (2) emotional abuse, family violence, and household incarceration; (3) physical and sexual abuse, family violence, and incarceration; (4) household dysfunction; and (5) higher ACEs (Wolff et al. 2018). Studies using data from the National Survey of Children's Health (NSCH) did not assess indicators of child maltreatment, but included parental death, racial discrimination, witnessing neighborhood violence, and family economic hardship. Using LCA with the NSCH data, Lanier et al. (2018) reported seven classes: low-risk with none or one ACE, domestic violence/no mental illness, mental illness/poverty, substance abuse/incarceration, substance abuse/no incarceration, moderate ACEs with one or two ACEs, and high ACEs with three or more. Another study reported fewer classes including (1) income hardship, (2) divorce, (3) mental health or substance abuse exposure, and (4) high ACEs overall (Lew and Xian 2019). Finally, researchers reported differing numbers and configurations of risk based on the child's race/ethnicity (Maguire-Jack et al. 2019). All classifications had a low- and a high-ACEs group; however, the additional latent classes were substantively different in content and number according to race/ethnicity.

These studies provide minimal evidence of a convergence of the co-occurrence of similar experiences. There are notable differences between studies, which are likely attributable to the variations in the measurement and definitions of the ACEs examined as well as the heterogeneity within and between the populations studied. All person-centered studies reported groups of individuals with low-risk and most reported highrisk exposures, but the co-occurrence of exposures to household dysfunctions and maltreatment varied across studies.

\section{The Current Study}

The primary goal of this study was to add to the existing literature examining dimensions of adversity through an examination of the interrelatedness of prospectively measured ACE exposures in early childhood. To achieve this goal, we will use person-centered analytic techniques to identify clusters of infants based on their ACE exposures and validate the identified clusters using additional parenting measures. We will examine the associations between ACE clusters and parenting stress, knowledge of infant development, and feelings of self-efficacy, as well as observed parent-child interactions. To our knowledge, we are the first study to examine the interrelatedness of ACEs using person-centered techniques with prospectively measured ACEs in infancy. Establishing clusters of risks for very young children provides the opportunity to reduce the overall number of ACEs screened and to prioritize screening questions based on strength of association, and could lead to tests of whether the clusters are differentially linked later developmental outcomes.

\section{Methods}

\section{Study Design}

This study is a secondary analysis of data from the Birth to Three Phase (1996-2001) of the Early Head Start Research and Evaluation Project (EHSRE). The EHSRE was a large-scale, random-assignment evaluation of Early Head Start (EHS), which is a twogeneration intervention developed to support optimal child development. The evaluation was conducted in 17 sites, which were selected to be representative of all programs funded with regard to setting (urban and rural) and intervention delivery (home-based, centerbased, and combination). Direct child assessments and observations of the parent-child relationships and the home environment, as well as interviews with parents about child and family functioning, were conducted at three different points in the children's development: 14 , 24, and 36 months of age. More detailed information regarding EHSRE has been described in earlier reports and publications (Love et al. 2002, 2005). EHS serves low-income pregnant women and families with children birth to age three. The EHSREP enrolled families who met the eligibility requirements (e.g., income at federal poverty) with random assignment to program (51\%) or comparison (49\%) groups. Randomization yielded equivalent groups. Families provided informed consent and the study was approved by the Institutional Review Boards of the participating universities.

Data for this study comes from assessments completed when the child was at or near 14 months of age. Data were collected in families' homes through structured interviews with parents, and semi-structured parent-child play interactions were videotaped and coded. Data collection staff demonstrated at least $85 \%$ consistency or reliability adherence of the EHSRE protocol. The independent EHSRE research team that scored parent interaction tapes reached an $85 \%$ reliability level (Fuligni et al. 2013; Love et al. 2002, 2005). 


\section{Sample Description}

As shown in Table 1, this study included any participant with data at the 14-month assessment $(N=2361)$. The sample was racially/ethnically diverse with $34.5 \%$ African-American, $22.9 \%$ Hispanic, $37.9 \%$ White, and $4.7 \%$ other. At enrollment into the EHSRE, primary caregivers were 22.7 years of age $(\mathrm{SD}=6)$ and about half $(45.7 \%)$ had not completed high school. Retention was 78\% (Love et al. 2002, 2005).

\section{Measures}

\section{Adverse Childhood Experiences}

As shown in Table 2, the EHS-ACE Index was computed to match the Kaiser-ACE study constructs (i.e., physical and emotional abuse/neglect, sexual abuse, household substance abuse, incarcerated household member, domestic violence, parental separation and divorce, and parental mental illness) as closely as possible (McKelvey et al. 2017, 2018, 2019). The EHS-ACE Index includes multiple single-item responses to hypothetical discipline situations, a stressful life events checklist, and several standardized instruments.

\section{Child Maltreatment ACEs}

Computations of child maltreatment ACEs included parent responses to hypothetical discipline situations and multiple standardized instruments, described as follows.

\section{Discipline}

Parents provided open-ended answers to how they would respond to hypothetical discipline situations with the child, including (1) the child keeps playing with breakable things and
(2) the child throws a temper tantrum in a public place. Responses were classified into the types of discipline strategies, which were coded as binary responses $(0=$ no, $1=$ yes $)$ each strategy that was ever mentioned. Open-ended responses that included shouting at the child, verbally punishing the child, and shaking the child were coded as emotional abuse, and slapping or psychically punishing the child was coded as physical abuse. Parents were also asked the number of times the child was spanked in the last week; responses of 7 or more spankings in the last week were included as a physical abuse indicator.

\section{Home Observation for Measurement of the Environment}

At 14 months, parenting behaviors were observed using the Infant-Toddler version of the Home Observation for Measurement of the Environment (HOME; Caldwell and Bradley 1984). The EHSRE included HOME observations of parental emotional and physical responsiveness to the child. In the EHSRE study, internal consistency reliability was high (0.76); however, individual items for the HOME were used in the construction of the EHS-ACE score as seen in Table 2.

\section{Three-Bag Task}

Also used in computations of child maltreatment ACEs were parent-child interaction behaviors during a semi-structured play task, the Three-Bag Task, during which the dyad was given three bags of toys and asked to play with the toys in sequence. The Three-Bag Task was videotaped, and behaviors were coded by child development researchers on a 7-point scale (Fuligni et al. 2013; Fuligni and Brooks-Gunn 2013). Detachment measures a lack of awareness, attention, and engagement with child and negative regard measures the expression of discontent with, anger toward, disapproval of, and/or

Table 1 Child, parent, and family characteristics by adverse childhood experience group membership

\begin{tabular}{|c|c|c|c|c|}
\hline & $\begin{array}{l}\text { Full sample } \\
(N=2361)\end{array}$ & $\begin{array}{l}\text { ACEs-low } \\
(N=1431)\end{array}$ & $\begin{array}{l}\text { ACEs-parent maltreatment } \\
(N=636)\end{array}$ & $\begin{array}{l}\text { ACEs-household dysfunction } \\
(N=294)\end{array}$ \\
\hline Parent age: years at child's birth $(M, \mathrm{SD})$ & $22.7(5.7)$ & $22.6(5.9)$ & $21.6(5.5)$ & $23.3(5.6)$ \\
\hline \multicolumn{5}{|l|}{ Race/ethnicity** } \\
\hline Caucasian & $37.9 \%$ & $43.3 \%$ & $29.4 \%$ & $40.5 \%$ \\
\hline African-American & $34.5 \%$ & $31.6 \%$ & $52.4 \%$ & $27.1 \%$ \\
\hline Hispanic & $22.9 \%$ & $18.6 \%$ & $15.3 \%$ & $27.2 \%$ \\
\hline Other & $4.7 \%$ & $6.5 \%$ & $2.9 \%$ & $5.4 \%$ \\
\hline \multicolumn{5}{|l|}{ Education** } \\
\hline Less than high school & $45.7 \%$ & $45.6 \%$ & $56.9 \%$ & $40.8 \%$ \\
\hline High school graduate or equivalent & $28.8 \%$ & $33.1 \%$ & $26.1 \%$ & $29.1 \%$ \\
\hline Some college or degree & $25.5 \%$ & $21.4 \%$ & $17.0 \%$ & $30.1 \%$ \\
\hline Child is male & $51.2 \%$ & $56.1 \%$ & $50.2 \%$ & $50.6 \%$ \\
\hline
\end{tabular}

$* * p<.001$ 
Table 2 Adverse childhood experiences at age 14 months $(N=2361)$ in the Early Head Start Research and Evaluation Project

1. Emotional abuse: Did a parent or other adult in the household often or $\mathrm{HO}$ very often swear at you, insult you, put you down, or humiliate you? or Act in a way that made you afraid that you might be physically hurt?

2. Physical Abuse: Did a parent or other adult in the household often or very often push, grab, slap, or throw something at you? or Ever hit you so hard that you had marks or were injured?

3. Sexual Abuse: Did an adult or person at least 5 years older than you ever touch or fondle you or have you touch their body in a sexual way? or Attempt or actually have oral, anal, or vaginal intercourse with you?

4. Emotional Neglect: Did you often or very often feel that no one in your family loved you or thought you were important or special? or Your family did not look out for each other, feel close to each other, or support each other?

5. Physical Neglect: Did you often or very often feel that you did not have enough to eat, had to wear dirty clothes, and had no one to protect you? or Your parents were too drunk or high to take care of you or take you to the doctor if you needed it?

6. Parental Separation: Were your parents ever separated or divorced?

7. Domestic Violence: Was your mother/stepmother often or very often pushed, grabbed, slapped, or had something thrown at her? or Sometimes, often, or very often kicked, bitten, hit with a fist, or hit with something hard? or Ever repeatedly hit over at least a few minutes or threatened with a gun or knife?

8. Substance Abuse: Did you live with anyone who was a problem drinker or alcoholic, or who used street drugs?

9. Household Mental Illness: Was a household member depressed or mentally ill, or did a household member attempt suicide?

10. Household Incarceration: Did a household member go to prison?

HOME Inventory ${ }^{\mathrm{b}}$ : Shouted at Child during Assessment; High Parent Negative Regard in Three-Bag Task ${ }^{\mathrm{c}}$; Hypothetical Discipline (Shout at, Punish verbally, Shake)

HOME Inventory ${ }^{\mathrm{b}}$ : Slapped/Spanked Child during Assessment; Hypothetical Discipline (Slap or physically punish); Child Spanked Daily

Child in Foster Care; Child Attacked

High Family Environment Scale ${ }^{\mathrm{d}}$ Family Conflict; High Parent Detachment in Three-Bag Task ${ }^{\mathrm{c}}$

HOME Inventory ${ }^{\text {b }}$ : Unsafe Play Environment and/or Did Not Keep Child in Visual Range

Current Relationship with Child's Father (Not in any Relationship, Separated/Divorced, Deceased)

Stress Checklist: Mother Abused

${ }^{\mathrm{a}}$ https://www.cdc.gov/violenceprevention/acestudy/about.html. ${ }^{\mathrm{b}}$ Bradley and Caldwell 1988. ${ }^{\mathrm{c}}$ Fuligni et al. 2013 ; Fuligni and Brooks-Gunn 2013.

${ }^{\mathrm{d}}$ Moos and Moos 1994. ${ }^{\mathrm{e}}$ Ross et al. 1983

rejection of the child. The intercoder agreement was high (94\%; Love et al. 2005). To be included as an ACE indicator, we included the most extreme condition (parents within the top $10 \%$ for negative interactions).

\section{Family Environment Scale}

Also included in child maltreatment ACEs is family conflict, assessed using one subscale from the Family Environment Scale (FES; Moos and Moos 1994). The conflict subscale measured the extent to which the open expression of anger, aggression, and conflictual interactions are characteristic of the family. In the EHSRE study, Cronbach's alpha was computed as 0.65 ( 1 year). The risk was defined as families scoring in the highest $10 \%$ of the distribution.

\section{Household Dysfunction ACEs}

Family functioning ACEs were primarily measured using a stressful life events checklist and parental depressive symptoms.

\section{Stressful Life Events}

The stressful life events checklist included a list of 20 events that had happened within the last year (US Department of Health and Human Services 1998). Parents reported a binary (yes/no) response to stressful life events, both positive (e.g., being married) and negative (e.g., having a relative or close friend jailed).

\section{Center for Epidemiological Studies Depression Scale-Short Form}

Parental mental illness was assessed using a measure of parental depression (the Center for Epidemiological Studies Depression Scale-Short Form (CESD-SF) (Ross et al. 1983). The scale includes 12 items that represent the number of days in the past week the participant experienced symptoms including poor appetite, restless sleep, loneliness, sadness, and lack of energy (Ross et al. 1983). The internal consistency of CESD-SF was high $(\alpha=0.88$; Love et al. 2005). For the 
CESD-SF, we used a cutoff score of 16 as an indicator of depression.

\section{Parenting Outcomes}

\section{Parenting Stress Index-Short Form}

The Parenting Stress Index-Short Form (PSI-SF) used in the EHSRE has been described in detail in other publications (McKelvey et al. 2009; Whiteside-Mansell et al. 2007). The PSI-SF has 36 items in three subscales: Parental distress, parent-child dysfunctional interaction, and difficult child. The EHSRE included two subscales: (1) parental distress (PD), which quantifies the distress a parent experiences as a function of individual personal characteristics in the parenting role, and (2) parent-child dysfunctional interaction (PCDI), which quantifies the parent's perceptions that interactions with the child are reinforcing to the parent (e.g., "child does not like me") and the child met his or her expectations, particularly as related to other children (e.g., smiles less). Internal consistency reliability in the EHSRE was high (PD $\alpha=.81$; PCDI $\alpha=.73$ ). Responses were summed so that higher scores indicated more of the construct.

\section{Self-efficacy}

The Pearlin Mastery Scale (Pearlin and Schooler 1978) was used to assess self-efficacy, which is a five-item scale that measures perceptions of the extent to which the respondent feels that he or she has control over their life. Respondents answered items such as "I can do just about anything I really set my mind to" on a four-point scale from 1 (strongly disagree) to 4 (strongly agree). Responses were summed such that higher scores indicated more perceived self-efficacy $(\alpha=.69)$.

\section{Knowledge of Infant Development}

To measure parents' knowledge of infant development, we used items adapted for the EHSRE from the Knowledge of Infant Development Inventory (MacPhee 1981). Parents record their response to nine questions about infant development. Responses were on a five-point scale with values of strongly agree (1) to strongly disagree (5). There was a correct response for each item so it was possible to score each based on how much the respondent agreed with the correct answer. In the EHSRE, the Knowledge of Infant Development Inventory (KIDI) was computed such that higher scores indicated more knowledge of infant development. The resulting scale had moderate internal consistency reliability $(\alpha=.71)$.

\section{Maternal Supportiveness}

Positive characteristics of parent-child interaction were also coded during the Three-Bag Task. Maternal supportiveness is a composite score of three highly correlated subscales: parental sensitivity (mother takes the child's perspective, accurately perceives the child's cues, and responds appropriately), cognitive stimulation (mother demonstrates teaching behaviors to increase the child's abilities), and positive regard (mother demonstrates love, respect, and admiration). Reliability of the scale was high $(\alpha=.79$; Fuligni et al. 2013; Fuligni and Brooks-Gunn 2013).

\section{Approach to Analysis}

Latent class analysis (LCA) was conducted to identify groups with distinct patterns of co-occurring ACE indicators. LCA models were estimated using Mplus 8.1 (Muthén and Muthén 2017). We used the Lo, Mendell, and Rubin likelihood ratio test (LMR) and the Bayesian information criterion (BIC) to identify the number of classes to retain. The LMR functions as an approximate hypothesis test wherein the null hypothesis is that no additional classes are needed (Lo et al. 2003). The BIC allows one to compare the relative model fits for competing models with smaller BIC values indicating superior model fit. Use of the LMR and BIC to identify the number of groups in LCA has been supported by previous work using Monte Carlo studies (Nylund et al. 2007). In addition, we considered the substantive meaning of the classes and the sample size of the classes. Based on the posterior probabilities provided by the latent class measurement model, group memberships were determined following the maximum-probability assignment rule (Nagin 2005), where individuals were assigned to the class for which they have the highest posterior probability of membership (Goodman 2007). These groups were used to interpret the meaning of groups based on ACE characteristics and test demographic differences in group membership.

While the traditional 3-step approach adjusts for classification error, statisticians have raised concerns over estimate attenuation as that approach does not include other variables in the classification process (Bolck et al. 2004). To account for this, a BCH (Bolck et al. 2004) approach was used to test how group membership was associated with key outcome parenting variables. This approach adjusts for classification error and reduced estimate attenuation by including all variables of interests in each model. After identifying the number of classes, we preserved $\mathrm{BCH}$ weights and used the weights as training data in the mixture model to examine associations between group membership and key parenting variables in the general auxiliary model conditional on the latent class groups using the $\mathrm{BCH}$ weights. All analyses included EHS program assignment and location of services, primary caregiver race, age, education, and child gender as covariates. The 
statistical significance of group differences on key parenting variables allowed us to determine whether the patterns of exposure are related to each of the parenting outcomes and whether group membership is similarly predictive for all types of outcomes.

\section{Results}

The LCA using the variables described in Table 2 resulted in a 3-class solution. The 3 -class solution had the smallest BIC value. The solution was supported by the statistically significant LMR tests in that a particular number of classes produced a significantly better fitting model than a model with one fewer classes: 2 classes $\mathrm{BIC}=19,819.83$, LMR $p<.001 ; 3$ classes $\mathrm{BIC}=19,779.97, \mathrm{LMR} p<.001 ; 4$ classes $\mathrm{BIC}=$ 19,835.83, LMR $p=0.184$; and 5 classes $\mathrm{BIC}=19,898.28$ LMR $p=0.215$.

Figure 1 shows the proportion of each of the three groups having each of the ten ACEs. The first of the three groups (ACEs-low, $N=1431, M=0.84, \mathrm{SD}=0.77,60.6 \%$ ) shows relatively low levels of ACE exposure with some elevation on physical neglect (27\%) and parent separation (17\%). For example, only $1 \%$ of this group exhibited emotional abuse compared with $37 \%$ and $14 \%$ in the other groups. The second ACE exposure group (ACEs-parent maltreatment, $N=636$, $M=2.91, \mathrm{SD}=1.06,26.9 \%$ ) has the highest levels of exposure to emotional abuse $(37 \%)$, physical abuse $(23 \%)$, and physical neglect $(57 \%)$ compared with rates of $1 \%, 6 \%$, and $27 \%$ respectively in the ACEs-low group and $14 \%, 15 \%$ and $42 \%$ respectively in the ACEs-household dysfunction group. The third group (ACEs-household dysfunction, $N=294, M=$ $3.94, S D=1.30,12.5 \%$ ) has the highest levels of exposure for parent separation $(36 \%)$, domestic violence $(53 \%)$, substance abuse $(55 \%)$, mental illness $(48 \%)$, and jailed family $(68 \%)$ compared with rates of $17 \%, 4 \%, 5 \%, 5 \%$, and $18 \%$ respectively in the ACEs-low group and 25\%,7\%,8\%, 21\%, and $42 \%$ respectively in ACEs-parent maltreatment group.

Table 1 includes the participant demographics by groups. The groups were not significantly different on the proportion assigned to the EHS treatment $\left(\chi^{2}(2)=3.31, p=.191\right)$ or the gender of the target child $\left(\chi^{2}(2)=1.03, p=.599\right)$. The groups were significantly different in level of maternal education $\left(\chi^{2}(4)=57.66, p<.001\right)$ with the lowest educated mothers being more likely in the ACEs-parent maltreatment group and higher educated mothers being more likely in the ACEshousehold dysfunction group. The groups were also different on race $\left(\chi^{2}(6)=133.42, p<.001\right)$ such that African-American mothers were more likely to be in the ACEs-parent maltreatment group, and Hispanic mothers were more likely to be in the ACEs-low group relative to other groups. For maternal age $(F(2,2341)=18.39, p<.001)$, the ACEs-low group had the oldest mothers (23.3 years, $\mathrm{SD}=5.6)$, and the ACEs-parent maltreatment group were the youngest $(21.6$ years, $\mathrm{SD}=5.5$ ). Each of these variables was entered as a covariate in subsequent analyses with group membership predicting parenting outcomes.

As seen in Table 3, ACE group membership was significantly associated with each of the parenting variables examined. We followed up each of the significant differences with post hoc pairwise least significant difference comparisons. Analysis of the PSI-SF resulted in significant differences in parent-reported parental distress $\left(\chi^{2}(2)=100.39, p<.001\right)$ and observed parent-child dysfunctional interaction $\left(\chi^{2}(2)=56.20, p<.001\right)$. For both measures, the ACEs-household dysfunction group had the
Fig. 1 Adverse childhood experience group membership by adverse indicator at age 14 months

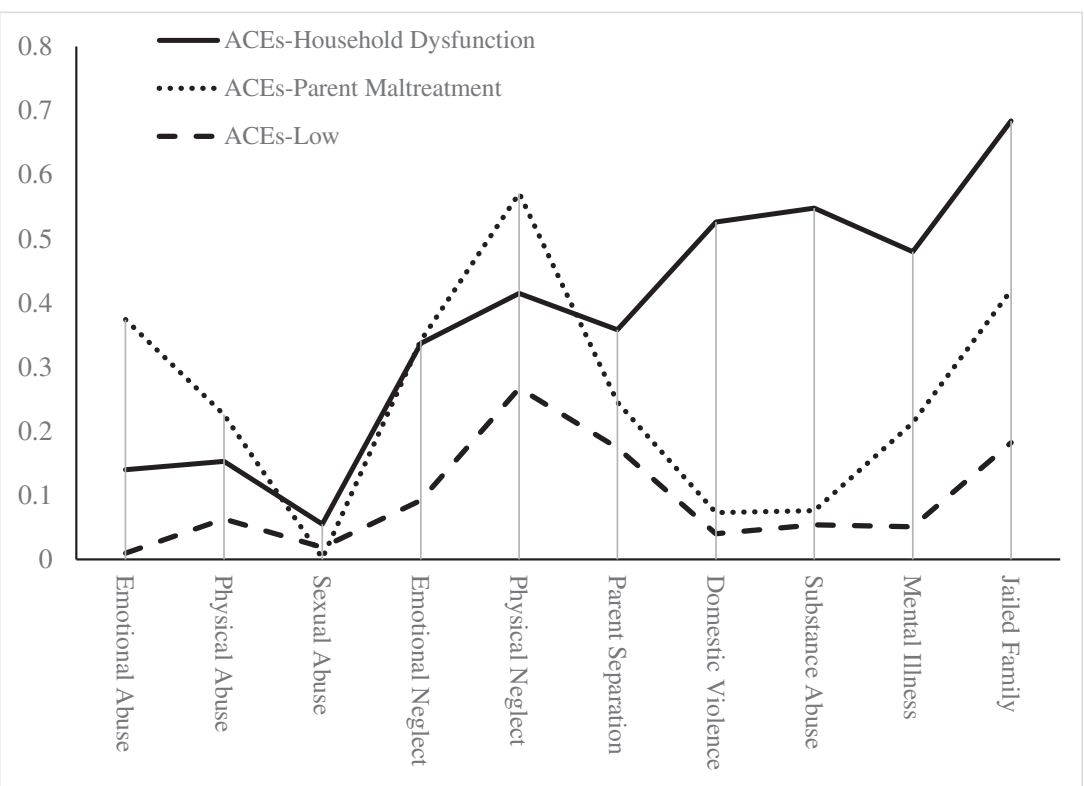


Table 3 Parenting at age 14 months by adverse childhood experience class membership

\begin{tabular}{llll}
\hline ACE classes & & & \\
\hline Parenting variable & ACEs-low & ACEs-parent maltreatment & $\begin{array}{l}\text { ACEs-household } \\
\text { dysfunction }\end{array}$ \\
\hline Parenting stress & & & \\
Parental distress scale** & $21.90_{\mathrm{a}}(1.39)$ & $27.08_{\mathrm{b}}(1.17)$ & $30.53_{\mathrm{c}}(1.63)$ \\
Parent-child dysfunctional interaction** & $16.20_{\mathrm{a}}(0.87)$ & $19.26_{\mathrm{b}}(0.74)$ & $19.84_{\mathrm{b}}(1.07)$ \\
Parenting knowledge and confidence & & & $3.34_{\mathrm{a}}(0.07)$ \\
Knowledge of infant development* & $3.31_{\mathrm{a}}(0.06)$ & $3.18_{\mathrm{b}}(0.05)$ & $13.93_{\mathrm{c}}(0.60)$ \\
Pearlin Mastery total score* & $17.75_{\mathrm{a}}(0.52)$ & $15.52_{\mathrm{b}}(0.43)$ & $4.15_{\mathrm{c}}(0.21)$ \\
Parent-child interaction & & & $3.18_{\mathrm{b}}(0.16)$ \\
Parent supportiveness* & $4.39_{\mathrm{a}}(0.20)$ & & \\
\hline
\end{tabular}

Estimated means (SEs) from BCH method with auxiliary variables in mixture models in columns. ${ }^{*} p<0.05$; $* * p<0.001$. Subscripts $\mathrm{a}, \mathrm{b}$, and $\mathrm{c}$ : means with different subscripts are significantly different $(p<.05)$. All analyses controlled for EHS program assignment and location of services, primary caregiver race, age, education, and child gender highest levels of parenting stress, the ACEs-parent maltreatment group had the next highest, and the ACEs-low group had the lowest level of parenting stress with all pairs significantly different. For the Knowledge of Infant Development Index $\left(\chi^{2}(2)=16.35, p<.001\right)$, the ACEsparent maltreatment group scored significantly lower than the ACEs-low group $(p=.001)$ while the ACEs-household dysfunction group was not significantly different from either of the other groups. For the Pearlin Mastery Scale $\left(\chi^{2}(2)=144.31, p<.001\right)$, those in the ACEs-low group showed the highest levels of self-efficacy, and individuals in the ACEs-parent maltreatment group had the next highest levels of self-efficacy, with the ACEs-household dysfunction group having the lowest levels of self-efficacy. All pairwise comparisons were statistically significant. For observed parent supportiveness $\left(\chi^{2}(2)=141.64\right.$, $p<.001)$ in semi-structured play, those in the ACEs-low group were most supportive, those in the ACEs-household dysfunction group had the next highest levels of support, and those in the ACEs-parent maltreatment group showed the lowest levels of supportiveness. All pairwise comparisons were statistically significant.

\section{Discussion}

Although our study was the first to examine the interrelatedness of adversities for infants, the findings were somewhat consistent with findings reported using BRFSS-ACEs data from adults (Brown et al. 2013; Ford et al. 2014; Merians et al. 2019; Mersky et al. 2017) and older children in pediatric visits with parent-reported Kaiser-ACEs (Scott et al. 2013). Our analysis identified a pattern of infants exposed to relatively low incidences of ACEs (low-ACEs). We also identified two clusters of higher ACE exposures for children: an ACEs- parent maltreatment cluster of children who experienced moderate level of ACEs with multiple correlates of maltreatment and an ACEs-household dysfunction cluster with the highest ACE scores who experienced multiple forms of family and household dysfunction.

The findings of this study demonstrate that co-occurring clusters of adversities in childhood are associated with other characteristics of the parenting environment. We found that children in the ACEs-low group experienced the most positive parenting environment; they lived with parents with the least parenting stress, high knowledge of development, and the greatest self-efficacy, and who were observed to be the most supportive of their children in play. Our study also identified important distinctions between the at-risk ACE groups and parenting resources that would support child development. Children in ACEs-household dysfunction families had parents who reported the greatest parenting stress and the least amount of self-efficacy, but who also reported an understanding of infant development similar to the ACEs-low parents and were observed to be moderately supportive in play. Children in ACEs-parent maltreatment families had parents who reported moderate levels of stress and self-efficacy, but who were the least knowledgeable of child development and were observed to be the least supportive in play.

\section{Implications for Intervention}

Studies of cumulative adversities have demonstrated the longterm importance of the experiences of childhood both on the quality of life of the individual and on the cost to society and families. The literature clearly demonstrates that the accumulation of adversities is a robust predictor of developmental outcomes. In efforts to understand the mechanisms underlying the developmental impacts of adversity and appropriately intervene, explorations of adversities have shifted to examining 
whether there are similar constellations of experiences of children. One theory for how risks differentially impact development is through understanding distinct dimensions of adversity, namely, whether the risk is a threat of harm or harm (i.e., traumatic) versus a deprivation from the environment (McLaughlin and Sheridan 2016).

The findings from our latent classes are supportive of infants being exposed to risks within these distinctions, albeit not exclusively. For example, infants in the ACEs-parent maltreatment group may be more likely to experience harm or threat of harm, while impacts on infants in the ACEshousehold dysfunction group may be more likely through deprivation. Moreover, examining additional parenting characteristics beyond the ACEs demonstrated additional variability for predicting possible child developmental outcomes. For example, while the group of infants in the ACEs-household dysfunction group has the highest level of ACE exposure overall, they also have caregivers who remain moderately supportive in interactions despite their lack of psychological resources. In this case, these supportive interactions with their caregiver may serve as a protective factor (Bethell et al. 2019).

When considering cumulative ACE impacts on the child, it has been shown that social-emotional development is negatively impacted by ACEs early in development and that those impacts are relatively persistent even to reductions in exposures later in development, at least within the infant-toddler years (McKelvey et al. 2017). However, in the same study, rebounds for cognitive and language development have been demonstrated. Therefore, it appears important to target interventions for specific developmental outcomes and to provide broader intervention to reduce cumulative risk of ACEs.

When considering interventions that support the parent and family, parenting stress and self-efficacy are often targeted levers for supporting child development in intervention programs (Bugental et al. 2002; McKelvey et al. 2015; Raikes et al. 2014; Sanders and Woolley 2005). For example, it is clearly established that parenting stress is associated with less optimal parent-child interactions (Abidin 1992; Coyl et al. 2002; Dearing et al. 2006; McKelvey et al. 2002) and an increased likelihood of child maltreatment and neglect (Browne and Saqi 1988; Holden and Banez 1996; Holden et al. 1989). Further, parents with a greater sense of selfefficacy have been shown to have more optimal parenting behavior and parent-child relationships (Sanders and Woolley 2005) compared with those with lower self-efficacy, who have been found to use overly harsh and coercive discipline techniques (Bugental et al. 2002). As such, our findings would suggest parents in households with greater ACEshousehold dysfunction report greater stress and feeling less in control of their lives, but this did not translate into the highest likelihood of demonstrating behaviors that are correlates of child maltreatment, at least with their infant children. Parents with greater ACEs-family dysfunction were observed to be significantly more supportive in interaction with their infants than parents in the ACEs-parent maltreatment group. Negative zero-order associations between knowledge of child development and parenting stress and behaviors have been shown in the literature (Belcher et al. 2007). While findings would need to be replicated, our person-centered analyses demonstrate that stress, self-efficacy, and knowledge of development may be differently associated with parent-child interaction based on other adversities in the family. The findings of this study demonstrate that knowledge may be a salient lever for change in that it may be serving a protective function for parents with greater household stressors. Perhaps knowledge of development could serve as a useful indicator for determining referral options. For example, families with lesser knowledge may need to receive more intensive parenting interventions in which direct support for optimal parent-child interactions could be provided, while caregivers with greater stress may benefit more from interventions that support their own psychological health.

\section{Implications for Screening and Identification}

This study advances our understanding of the interrelatedness of ACEs and represents the first study of children in infancy. As outlined above, the negative effects of ACEs on physical and psychological health are pervasive (Kerker et al. 2015; McKelvey et al. 2016, 2017; Shonkoff et al. 2012). The American Academy of Pediatrics recommends that pediatric medical homes adopt a range of activities meant to reduce children's experiences and/or effects of adversities and toxic stress, including screening (Garner et al. 2012). There are barriers to screening children's adversities in clinical settings, though, some of which include (1) the time required to complete the screen, (2) not knowing the most useful age to screen, (3) having tools that are feasible and valid, and (4) having resources in place when children are identified by the screening (Marie-Mitchell et al. 2019; McKelvey et al. 2016, 2017).

Together, these studies of the clusters of ACEs experienced by children lend some support to a reduction in screening items that could be used in practice. Work has been conducted with retrospective self-reports by adults using the BRFSSACEs to develop a short form (Wade et al. 2017). The authors developed a two-item BRFSS-ACE screener, household alcohol, and child emotional abuse, which could be used to determine the need for additional screening. Screening children prospectively is inherently more complicated than asking adults about their childhoods. For one, ACEs are sensitive in nature, especially when asking a parent to report about highly stigmatized and potentially illegal (e.g., child maltreatment and drug/alcohol addiction) behaviors (McKelvey et al. 2016). There are also decisions that must be made about whether the questions are lifelong, historical experiences or measure current risks to facilitate additional family supports 
(Marie-Mitchell et al. 2019; McKelvey et al. 2016). There is recent evidence that prospective measures are more salient for predicting health outcomes than retrospective measures (Reuben et al. 2016), but there is still variability as to how ACEs are assessed in childhood. The use of prospective measurement also provides the opportunity for timely support of the family to create positive change for the child, such as providing referrals for parental depression or domestic violence (Marie-Mitchell et al. 2016, 2019; McKelvey et al. 2016). As the field coalesces around the measurement of ACEs in pediatric populations, the development of a short form such as what was conducted with the BRFSS-ACEs to reduce the items used in clinical settings could support more widespread implementation of screening. Indeed, the findings from this study could be used to make the screenings shorter and more sensitive, as parental incarceration and emotional abuse appear to be potential constructs that most meaningfully predict the need for additional questions.

\section{Strengths and Limitations}

There are several strengths highlighted in the current study. The findings of our study add to the growing literature on ACEs in several ways. It is the first to examine the interrelatedness of ACEs using a large, national sample of the youngest population (infants) and their families in both rural and urban settings. Examining the cluster of risks on a narrow age range of children allowed us to examine the co-occurrence of risks in early childhood compared with other studies that included a wide range of ages and definition of experiences. The measure of ACEs used in the current study was computed using prospective items, which permit the development of additional tools to identify children and families in need of additional supports. Further, to achieve higher reliability for our findings, the identified groups were validated with both parent self-reports and observed behavior measures. Finally, the study employed a rigorous methodology, using a person-centered approach to examine the interrelatedness of risk and to explore the associations between identified ACE groups and parenting beliefs and behaviors.

Alongside these strengths, there are also limitations to be noted. The families in this study were eligible for EHS making them at greater socio-economic risk than families from the general population. Thus, the study should be replicated in a more economically diverse sample. There were no differences between group membership for children randomly assigned to EHS and the comparison group. Our analyses controlled for EHS intervention to adjust for possible program influences, but future studies could explore whether there is change in cluster membership as children age in both the EHS intervention and comparison conditions.

While the indicators of ACEs used in the current study match the Kaiser-ACEs (Anda et al. 2006; CDC n.d.; Felitti et al. 1998), it is important to note that the measure of ACEs in the current study is qualitatively different from many of those used in the existing literature. Rather than a historical report of ACEs, the EHSRE-ACE tool uses prospective parent-report and observation methods of correlates of or proxies for the Kaiser-ACEs. Therefore, the EHS-ACE index used in the current study did not directly document child abuse and neglect of the children, and our findings are not directly comparable with data from child welfare samples. However, the computation of EHSRE-ACEs used in the current study has been found associated with the same outcomes as studies using other ACE measurements, including those in child welfare samples. The similarity of our findings with the existing literature provides additional evidence that ACEs can be assessed using proxy variables that are associated with, but do not directly ask about, abuse, neglect, or other illegal or stigmatized behaviors. There is research evidence that suggests prospective measures are more robust predictors of individuals' outcomes than retrospective reports (Reuben et al. 2016), but it is important to be aware of this distinction when comparing studies. Further, comparisons of our study to other studies in pediatric populations should keep in mind potential confounds between definitions (e.g., our sample would always have one ACE, poverty, using the NSCH-ACE measure).

\section{Conclusions}

Interventions must focus on improving the life course of children exposed to adversity. This will require novel approaches to sensitive screening to identify families and children who need additional supports, as well as novel approaches to intervention. Our study suggests that children are likely to experience constellations of ACEs, which are differentially associated with other parenting characteristics. Our study also supports the usefulness of ACE measurement that occurs prospectively using proxy variables that are associated with, but do not directly ask about child maltreatment and other illegal, stigmatized behaviors. Prospective, family-centered screenings could be integrated into pediatric medical, early care and education, and parent education settings (Marie-Mitchell and O'Connor 2013; McKelvey et al. 2016) allowing for intervention very early in life. With a greater understanding of the co-occurrence of ACEs, additional work to develop efficient and effective method screening is needed.

Acknowledgments Findings reported here are based on research conducted as part of the national Early Head Start Research and Evaluation Project funded by the U.S. Department of Health and Human Services (HHS) Administration for Children and Families (ACF) under Contract 105-95-1936 to Mathematica Policy Research, Princeton, NJ, and Columbia University's Center for Children and Families, Teachers College, in conjunction with the Early Head Start Research Consortium. The consortium consists of representatives from 17 programs participating in the evaluation, 15 local research teams, the evaluation contractors, and ACF. Research institutions in the consortium include ACF; Catholic University of America; Columbia University; 
Harvard University; Mathematica Policy Research; Medical University of South Carolina; Michigan State University; New York University; NPC Research; University of Arkansas; University of California at Los Angeles; University of Colorado Health Sciences Center; University of Missouri-Columbia; University of Pittsburgh; University of Washington College of Education; University of Washington School of Nursing; and Utah State University.

Funding Information This work was supported by the Health Resources and Services Administration (HRSA) of the US Department of Health and Human Services of the Maternal and Child Health Bureau (R40MC29441)

\section{Compliance with Ethical Standards}

Families provided informed consent and the study was approved by the Institutional Review Boards of the participating universities.

Conflict of Interest The authors declare that they have no conflict of interest.

Disclaimer This information or content and conclusions are those of the author and should not be construed as the official position or policy of, nor should any endorsements be inferred by HRSA, ACF, HHS, or the US Government.

Open Access This article is licensed under a Creative Commons Attribution 4.0 International License, which permits use, sharing, adaptation, distribution and reproduction in any medium or format, as long as you give appropriate credit to the original author(s) and the source, provide a link to the Creative Commons licence, and indicate if changes were made. The images or other third party material in this article are included in the article's Creative Commons licence, unless indicated otherwise in a credit line to the material. If material is not included in the article's Creative Commons licence and your intended use is not permitted by statutory regulation or exceeds the permitted use, you will need to obtain permission directly from the copyright holder. To view a copy of this licence, visit http://creativecommons.org/licenses/by/4.0/.

\section{References}

Abidin, R. R. (1992). The determinants of parenting behavior. Journal of Clinical Child Psychology, 21(4), 407-412. https://doi.org/10.1207/ s15374424jecp2104_12.

Anda, R. F., Felitti, V. J., Bremner, J. D., Walker, J. D., Whitfield, C., Perry, B. D., Dube, S. R., \& Giles, W. H. (2006). The enduring effects of abuse and related adverse experiences in childhood: a convergence of evidence from neurobiology and epidemiology. European Archives of Psychiatry and Clinical Neuroscience, 256(3), 174-186. https://doi.org/10.1007/s00406-005-0624-4.

Armour, C., Elklit, A., \& Christoffersen, M. N. (2014). A latent class analysis of childhood maltreatment: identifying abuse typologies. Journal of Loss and Trauma, 19(1), 23-39. https://doi.org/10. 1080/15325024.2012.734205.

Barboza, G. E. (2018). Latent classes and cumulative impacts of adverse childhood experiences. Child Maltreatment, 23(2), 111-125. https:// doi.org/10.1177/1077559517736628.

Belcher, H. M. E., Watkins, K., Johnson, E., \& Ialongo, N. (2007). Early head start: factors associated with caregiver knowledge of child development, parenting behavior, and parenting stress. NHSA Dialog, 10(1), 6-19. https://doi.org/10.1080/15240750701301639.

Belsky, J. (1984). The determinants of parenting: a process model. Child Development, 55(1), 83-96 http://www.ncbi.nlm.nih.gov/pubmed/ 6705636.

Berzenski, S. R., \& Yates, T. M. (2011). Classes and consequences of multiple maltreatment. Child Maltreatment, 16(4), 250-261. https:// doi.org/10.1177/1077559511428353.

Bethell, C. D., Simpson, L. A., \& Solloway, M. R. (2017). Child wellbeing and adverse childhood experiences in the United States. Academic Pediatrics, 17(7), S1-S3. https://doi.org/10.1016/j.acap. 2017.06.011.

Bethell, C. D., Gombojav, N., \& Whitaker, R. C. (2019). Family resilience and connection promote flourishing among US children, even amid adversity. Health Affairs, 38(5), 729-737. https://doi.org/10. 1377/hlthaff.2018.05425.

Bolck, A., Croon, M., \& Hagenaars, J. (2004). Estimating latent structure models with categorical variables: one-step versus three-step estimators. In Political Analysis. https://doi.org/10.1093/pan/mph001.

Bradley, R. H., \& Caldwell, B. M. (1988). Using the home inventory to assess the family environment. Pediatric Nursing, 14(2), 97-102.

Bradley, R. H., \& Corwyn, R. F. (2002). Socioeconomic status and child development. Annual Review of Psychology, 53, 371-399. https:// doi.org/10.1146/annurev.psych.53.100901.135233.

Brown, M. J., Thacker, L. R., \& Cohen, S. A. (2013). Association between adverse childhood experiences and diagnosis of cancer. PLOS One, 8(6), e65524. https://doi.org/10.1371/journal.pone.0065524.

Browne, K., \& Saqi, S. (1988). Mother-infant interaction and attachment in physically abusing families. Journal of Reproductive and Infant Psychology, 6(3), 163-182. https://doi.org/10.1080/ 02646838808403554 .

Bugental, D. B., Ellerson, P. C., Lin, E. K., Rainey, B., Kokotovic, A., \& O'Hara, N. (2002). A cognitive approach to child abuse prevention. Journal of Family Psychology, 16(3), 243-258. https://doi.org/10. 1037/2152-0828.1.S.84.

Caldwell, B. M., \& Bradley, R. H. (1984). Administration manual: home observation for measurement of the environment. Little Rock: University of Arkansas at Little Rock.

CDC. (n.d.). About the CDC-Kaiser ACE Study |Violence Prevention|Injury Center|CDC. Retrieved February 5, 2020, from Violence Prevention page website: https://www.cdc.gov/ violenceprevention/childabuseandneglect/acestudy/about.html.

Centers for Disease Control and Prevention. (2016). About Behavioral Risk Factor Surveillance System ACE Data. Retrieved March 19, 2019, from https://www.cdc.gov/violenceprevention/ childabuseandneglect/acestudy/ace-brfss.html.

Coyl, D. D., Roggman, L. A., \& Newland, L. A. (2002). Stress, maternal depression, and negative mother-infant interactions in relation to infant attachment. Infant Mental Health Journal, 23(1-2), 145163. https://doi.org/10.1002/imhj.10009.

Dearing, E., McCartney, K., \& Taylor, B. (2006). Within-child associations between family income and externalizing and internalizing problems. Developmental Psychology, 42(2), 237-252. https://doi. org/10.1037/0012-1649.42.2.237.

Dong, M., Anda, R. F., Dube, S. R., Giles, W. H., \& Felitti, V. J. (2003). The relationship of exposure to childhood sexual abuse to other forms of abuse, neglect, and household dysfunction during childhood. Child Abuse and Neglect, 27(6), 625-639. https://doi.org/10. 1016/S0145-2134(03)00105-4.

Dong, M., Anda, R. F., Felitti, V. J., Dube, S. R., Williamson, D. F., Thompson, T. J., Loo, C. M., \& Giles, W. H. (2004). The interrelatedness of multiple forms of childhood abuse, neglect, and household dysfunction. Child Abuse and Neglect, 28(7), 771-784. https://doi. org/10.1016/j.chiabu.2004.01.008.

Edwards, V. J., Holden, G. W., Felitti, V. J., \& Anda, R. F. (2003). Relationship between multiple forms of childhood maltreatment 
and adult mental health in community respondents: Results from the adverse childhood experiences study. American Journal of Psychiatry, 160(8), 1453-1460. https://doi.org/10.1176/appi.ajp. 160.8.1453.

Evans, G. W., Li, D., \& Whipple, S. S. (2013). Cumulative risk and child development. Psychological Bulletin, 139(6), 1342-1396. https:// doi.org/10.1037/a0031808.

Felitti, V. J. (1993). Childhood sexual abuse, depression, and family dysfunction in adult obese patients: a case control study. Southern Medical Journal, 86(7), 732-736. https://doi.org/10.1097/ 00007611-199307000-00002.

Felitti, V. J., Anda, R. F., Nordenberg, D., Williamson, D. F., Spitz, A. M., Edwards, V., Koss, M. P., \& Marks, J. S. (1998). Relationship of childhood abuse and household dysfunction to many of the leading causes of death in adults: the adverse childhood experiences (ACE) study. American Journal of Preventive Medicine, 14(4), 245-258. https://doi.org/10.1016/S0749-3797(98)00017-8.

Ford, D. C., Merrick, M. T., Parks, S. E., Breiding, M. J., Gilbert, L. K., Edwards, V. J., Dhingra, S. S., Barile, J. P., \& Thompson, W. W. (2014). Examination of the factorial structure of adverse childhood experiences and recommendations for three subscale scores. Psychology of Violence, 4(4), 432-444. https://doi.org/10.1037/ a0037723.

Fuligni, A. S., \& Brooks-Gunn, J. (2013). Mother-child interactions in early head start: age and ethnic differences in low-income dyads. Parenting, 13(1), 1-26. https://doi.org/10.1080/15295192.2013. 732422 .

Fuligni, A. S., Brady-Smith, C., Tamis-LeMonda, C. S., Bradley, R. H., Chazan-Cohen, R., Boyce, L., \& Brooks-Gunn, J. (2013). Patterns of supportive mothering with 1-, 2-, and 3-year-olds by ethnicity in early head start. Parenting, 13(1), 44-57. https://doi.org/10.1080/ 15295192.2013.732434.

Garner, A. S., Shonkoff, J. P., Siegel, B. S., Dobbins, M. I., Earls, M. F., Garner, A. S., McGuinn, L., Pascoe, J., \& Wood, D. L. (2012). Early childhood adversity, toxic stress, and the role of the pediatrician: translating developmental science into lifelong health. Pediatrics, 129(1), e224-e231. https://doi.org/10.1542/peds.2011-2662.

Goodman, L. A. (2007). On the assignment of individuals to latent classes. Sociological Methodology, 37(1), 1-22. https://doi.org/10.1111/ j.1467-9531.2007.00184.x.

Green, J. G., McLaughlin, K. A., Berglund, P. A., Gruber, M. J., Sampson, N. A., Zaslavsky, A. M., \& Kessler, R. C. (2010). Childhood adversities and adult psychiatric disorders in the National Comorbidity Survey Replication I. Archives of General Psychiatry, 67(2), 113. https://doi.org/10.1001/archgenpsychiatry. 2009.186.

Health Resources and Services Administration. (2019). National Survey of Children's Health Fact Sheet | October 2019. https://mchb.hrsa. gov/sites/default/files/mchb/Data/NSCH/NSCH-2018-factsheet.pdf

Hildyard, K. L., \& Wolfe, D. A. (2002). Child neglect: developmental issues and outcomes. Child Abuse and Neglect, 26(6-7), 679-695. https://doi.org/10.1016/S0145-2134(02)00341-1.

Holden, E., \& Banez, G. (1996). Child abuse potential and parenting stress within maltreating families. Journal of Family Violence, 11(1), 1-12. https://doi.org/10.1007/BF02333337.

Holden, E., Willis, D., \& Foltz, L. (1989). Child abuse potential and parenting stress: relationships in maltreating parents. A Journal of Consulting and Clinical Psychology, 1(1), 64-67. https://doi.org/10. 1037/1040-3590.1.1.64.

Kerker, B. D., Zhang, J., Nadeem, E., Stein, R. E. K., Hurlburt, M. S., Heneghan, A., Landsverk, J., \& McCue Horwitz, S. (2015). Adverse childhood experiences and mental health, chronic medical conditions, and development in young children. Academic Pediatrics, 15(5), 510-517. https://doi.org/10.1016/j.acap.2015.05.005.

Lanier, P., Maguire-Jack, K., Lombardi, B., Frey, J., \& Rose, R. A. (2018). Adverse childhood experiences and child health outcomes: comparing cumulative risk and latent class approaches. Maternal and Child Health Journal, 22(3), 288-297. https://doi.org/10. 1007/s10995-017-2365-1.

Lew, D., \& Xian, H. (2019). Identifying distinct latent classes of adverse childhood experiences among US children and their relationship with childhood internalizing disorders. Child Psychiatry and Human Development, 50(4), 668-680. https://doi.org/10.1007/ s10578-019-00871-y.

Lo, Y., Mendell, N. R., \& Rubin, D. B. (2003). Testing the number of components in a normal mixture. Biometrika, 88(3), 767-778. https://doi.org/10.1093/biomet/88.3.767.

Love, J. M., Kisker, E. E., Ross, C., Schochet, P., Brooks-Gunn, J., Paulsell, D., Boller, K., Constantine, J., Vogel, C. A., Fuligni, A. S., \& Brady-Smith, C. (2002). Making a difference in the lives of infants and toddlers and their families: the impacts of early head start. Volumes I-III: Final Technical Report [and] Appendixes [and] Local Contributions to Understanding the Programs and Their. Retrieved October 16, 2015, from https://www.acf.hhs.gov/ sites/default/files/opre/impacts voll.pdf.

Love, J. M., Kisker, E. E., Ross, C., Raikes, H., Constantine, J., Boller, K., Brooks-Gunn, J., Chazan-Cohen, R., Tarullo, L. B., BradySmith, C., Fuligni, A. S., Schochet, P. Z., Paulsell, D., Vogel, C., Raikes, H., Brooks-Gunn, J., Tarullo, L. B., Schochet, P. Z., Paulsell, D., \& Vogel, C. (2005). The effectiveness of early head start for 3year-old children and their parents: lessons for policy and programs. Developmental Psychology, 41(6), 885-901. https://doi.org/10. 1037/0012-1649.41.6.885.

MacPhee, D. (1981). Manual: knowledge of infant development inventory. Unpublished manuscript. Chapel Hill: University of North Carolina.

Maguire-Jack, K., Lanier, P., \& Lombardi, B. (2019). Investigating racial differences in clusters of adverse childhood experiences. American Journal of Orthopsychiatry. https://doi.org/10.1037/ort0000405.

Marie-Mitchell, A., \& O'Connor, T. G. (2013). Adverse childhood experiences: translating knowledge into identification of children at risk for poor outcomes. Academic Pediatrics, 13(1), 14-19. https://doi. org/10.1016/j.acap.2012.10.006.

Marie-Mitchell, A., Studer, K. R., \& O'Connor, T. G. (2016). How knowledge of adverse childhood experiences can help pediatricians prevent mental health problems. Families, Systems \& Health : The Journal of Collaborative Family Healthcare, 34(2), 128-135. https://doi.org/10.1037/fsh0000179.

Marie-Mitchell, A., Lee, J., Siplon, C., Chan, F., Riesen, S., \& Vercio, C. (2019). Implementation of the whole child assessment to screen for adverse childhood experiences. Global Pediatric Health, 6, 2333794X1986209. https://doi.org/10.1177/2333794X19862093.

McKelvey, L. M., Fitzgerald, H. E., Schiffman, R. F., \& Von Eye, A. (2002). Family stress and parent-infant interaction: the mediating role of coping. Infant Mental Health Journal, 23(1-2), 164-181. https://doi.org/10.1002/imhj.10010.

McKelvey, L. M., Whiteside-Mansell, L., Faldowski, R. A., Shears, J., Ayoub, C., \& Hart, A. D. (2009). Validity of the short form of the parenting stress index for fathers of toddlers. Journal of Child and Family Studies, 18(1), 102-111. https://doi.org/10.1007/s10826008-9211-4.

McKelvey, L. M., Schiffman, R. F., Brophy-Herb, H. E., Bocknek, E. L., Fitzgerald, H. E., Reischl, T. M., Hawver, S., Cunningham Deluca, M., London Bocknek, E., Fitzgerald, H. E., Reischl, T. M., Hawver, S., \& Deluca, M. C. (2015). Examining long-term effects of an infant mental health home-based early head start program on family strengths and resilience. Infant Mental Health Journal, 36(4), 353365. https://doi.org/10.1002/imhj.21518.

McKelvey, L. M., Whiteside-Mansell, L., Conners-Burrow, N. A., Swindle, T., \& Fitzgerald, S. (2016). Assessing adverse experiences from infancy through early childhood in home visiting programs. 
Child Abuse and Neglect, 51, 295-302. https://doi.org/10.1016/j. chiabu.2015.09.008.

McKelvey, L. M., Selig, J. P., \& Whiteside-Mansell, L. (2017). Foundations for screening adverse childhood experiences: exploring patterns of exposure through infancy and toddlerhood. Child Abuse and Neglect, 70, 112-121. https://doi.org/10.1016/j.chiabu.2017.06. 002 .

McKelvey, L. M., Edge, N. C., Mesman, G. R., Whiteside-Mansell, L., \& Bradley, R. H. (2018). Adverse experiences in infancy and toddlerhood: Relations to adaptive behavior and academic status in middle childhood. Child Abuse \& Neglect, 82, 168-177. https://doi.org/10. 1016/j.chiabu.2018.05.026.

McKelvey, L. M., Saccente, J. E., \& Swindle, T. M. (2019). Adverse childhood experiences in infancy and toddlerhood predict obesity and health outcomes in middle childhood. Childhood Obesity. https://doi.org/10.1089/chi.2018.0225.

McLaughlin, K. A., \& Sheridan, M. A. (2016). Beyond cumulative risk: a dimensional approach to childhood adversity. Current Directions in Psychological Science, 25(4), 239-245. https://doi.org/10.1177/ 0963721416655883.

McLaughlin, K. A., Greif Green, J., Gruber, M. J., Sampson, N. A., Zaslavsky, A. M., \& Kessler, R. C. (2012). Childhood adversities and first onset of psychiatric disorders in a national sample of US adolescents. Archives of General Psychiatry, 69(11), 1151-1160. https://doi.org/10.1001/archgenpsychiatry.2011.2277.

Merians, A. N., Baker, M. R., Frazier, P., \& Lust, K. (2019). Outcomes related to adverse childhood experiences in college students: comparing latent class analysis and cumulative risk. Child Abuse and Neglect, 87, 51-64. https://doi.org/10.1016/j.chiabu.2018.07.020.

Mersky, J. P., Janczewski, C. E., \& Topitzes, J. (2017). Rethinking the measurement of adversity: moving toward second-generation research on adverse childhood experiences. Child Maltreatment, 22(1), 58-68. https://doi.org/10.1177/1077559516679513.

Moos, R., \& Moos, B. (1994). Family environment scale manual: development, applications, research (Third ed.). Consulting Psychologist Press.

Muthén, L. K., \& Muthén, B. O. (2017). Mplus user’s guide (Eighth ed.). Los Angeles: Muthén \& Muthén. https://doi.org/10.1111/j.16000447.2011.01711.x.

Nagin, D. S. (2005). Group-based modeling of development. Harvard University Press.

Nylund, K. L., Asparouhov, T., \& Muthén, B. O. (2007). Deciding on the number of classes in latent class analysis and growth mixture modeling: aMonte Carlo simulation study. Structural Equation Modeling, 14(4), 535-569. https://doi.org/10.1080/10705510701575396.

Pearlin, L. I., \& Schooler, C. (1978). The structure of coping. Source: Journal of Health and Social Behavior Journal of Health and Social Behavior, 19(19), 2-212 http://www.jstor.org/stable/2136319.

Raikes, H. H., Roggman, L. a., Peterson, C. a., Brooks-Gunn, J., ChazanCohen, R., Zhang, X., \& Schiffman, R. F. (2014). Theories of change and outcomes in home-based Early Head Start programs. Early Childhood Research Quarterly, 29(4), 574-585. https://doi. org/10.1016/j.ecresq.2014.05.003.

Rebbe, R., Nurius, P. S., Ahrens, K. R., \& Courtney, M. E. (2017). Adverse childhood experiences among youth aging out of foster care: a latent class analysis. Children and Youth Services Review, 74, 108-116. https://doi.org/10.1016/j.childyouth.2017.02.004.

Reuben, A., Moffitt, T. E., Caspi, A., Belsky, D. W., Harrington, H., Schroeder, F., Hogan, S., Ramrakha, S., Poulton, R., \& Danese, A. (2016). Lest we forget: comparing retrospective and prospective assessments of adverse childhood experiences in the prediction of adult health. Journal of Child Psychology and Psychiatry, and Allied Disciplines, 57(10), 1103-1112. https://doi.org/10.1111/jcpp.12621.

Rivera, P. M., Fincham, F. D., \& Bray, B. C. (2018). Latent classes of maltreatment: a systematic review and critique. Child Maltreatment, 23(1), 3-24. https://doi.org/10.1177/1077559517728125.
Roos, L. E., Afifi, T. O., Martin, C. G., Pietrzak, R. H., Tsai, J., \& Sareen, J. (2016). Linking typologies of childhood adversity to adult incarceration: findings from a nationally representative sample. American Journal of Orthopsychiatry, 86(5), 584-593. https://doi.org/10. 1037/ort0000144.

Ross, C. E., Mirowsky, J., \& Huber, J. (1983). Dividing work, sharing work, and in-between: marriage patterns and depression. American Sociological Review, 48(6), 809-823. https://doi.org/10.2307/ 2095327.

Ross, J., Waterhouse-Bradley, B., Contractor, A. A., \& Armour, C. (2018). Typologies of adverse childhood experiences and their relationship to incarceration in U.S. military veterans. Child Abuse and Neglect, 79, 74-84. https://doi.org/10.1016/j.chiabu.2018.01.023.

Sanders, M. R., \& Woolley, M. L. (2005). The relationship between maternal self-efficacy and parenting practices: implications for parent training. Child: Care, Health and Development, 31(1), 65-73. https://doi.org/10.1111/j.1365-2214.2005.00487.x.

Sandler, I. (2001). Quality and ecology of adversity as common mechanisms of risk and resilience. American Journal of Community Psychology, 29(1), 19-61. https://doi.org/10.1023/A: 1005237110505 .

Schilling, C., Weidner, K., Schellong, J., Joraschky, P., \& Pöhlmann, K. (2015). Patterns of childhood abuse and neglect as predictors of treatment outcome in inpatient psychotherapy: a typological approach. Psychopathology, 48(2), 91-100. https://doi.org/10.1159/ 000368121.

Scott, B. G., Burke, N. J., Weems, C. F., Hellman, J. L., \& Carrión, V. G. (2013). The interrelation of adverse childhood experiences within an at-risk pediatric sample. Journal of Child \& Adolescent Trauma, 6(3), 217-229. https://doi.org/10.1080/19361521.2013.811459.

Shin, S. H., McDonald, S. E., \& Conley, D. (2018). Patterns of adverse childhood experiences and substance use among young adults: a latent class analysis. Addictive Behaviors, 78, 187-192. https://doi. org/10.1016/j.addbeh.2017.11.020.

Shonkoff, J. P. (2010). Building a new biodevelopmental framework to guide the future of early childhood policy. Child Development, 81(1), 357-367. https://doi.org/10.1111/j.1467-8624.2009.01399.x.

Shonkoff, J. P., Garner, A. S., Siegel, B. S., Dobbins, M. I., Earls, M. F., Garner, A. S., McGuinn, L., Pascoe, J., \& Wood, D. L. (2012). The lifelong effects of early childhood adversity and toxic stress. Pediatrics, 129(1), e232-e246. https://doi.org/10.1542/peds.20112663.

Springer, K. W., Sheridan, J., Kuo, D., \& Carnes, M. (2007). Long-term physical and mental health consequences of childhood physical abuse: results from a large population-based sample of men and women. Child Abuse and Neglect, 31(5), 517-530. https://doi.org/ 10.1016/j.chiabu.2007.01.003.

US Department of Health and Human Services. (1998). Early Head Start Parent Interview: for parents of 14-month-old infants. Retrieved January 11, 2020, from https://www.acf.hhs.gov/sites/default/files/ opre/parents_of_14month_0.pdf.

Wade, R., Becker, B. D., Bevans, K. B., Ford, D. C., \& Forrest, C. B. (2017). Development and evaluation of a short adverse childhood experiences measure. American Journal of Preventive Medicine, 52(2), 163-172. https://doi.org/10.1016/j.amepre.2016.09.033.

Whiteside-Mansell, L., Ayoub, C., McKelvey, L. M., Faldowski, R. A., Hart, A., \& Shears, J. (2007). Parenting stress of low-income parents of toddlers and preschoolers: psychometric properties of a short form of the parenting stress index. Parenting, 7(1), 26-56. https:// doi.org/10.1080/15295190709336775.

Wolff, K. T., Cuevas, C., Intravia, J., Baglivio, M. T., \& Epps, N. (2018). The effects of neighborhood context on exposure to adverse childhood experiences (ACE) among adolescents involved in the juvenile justice system: latent classes and contextual effects. Journal of Youth and Adolescence, 47(11), 2279-2300. https://doi.org/10.1007/ s10964-018-0887-5. 